\title{
The Right Visual Field Advantage and the Optimal Viewing Position Effect: On the Relation Between Foveal and Parafoveal Word Recognition
}

\author{
Marc Brysbaert \\ University of Leuven, Leuven, Belgium \\ Walter Schroyens \\ University of Leuven, Leuven, Belgium
}

Françoise Vitu

Université René Descartes, Paris

\begin{abstract}
Recent developments on the optimal viewing position (OVP) effect suggest that it may be caused by the same factors that underlie the right visual field advantage in word recognition. This raises the question of the relationship between foveal and parafoveal word recognition. Three experiments are reported in which participants identified tachistoscopically presented words that were presented randomly in foveal and parafoveal vision. The results show that both the OVP effect and the right visual field advantage for word recognition are part of a larger extended OVP curve that has the shape of a Gaussian distribution with the mode shifted to the left of the center of the stimulus word. The shift of the distribution is a function of word length, but not of presentation duration; it is also slightly moderated by the information value of word beginning and word end.
\end{abstract}

Tachistoscopic visual half ficld (VHF) studies are frequently used to assess the laterality of cognitive functions. They are based on the fact that stimuli presented in the left half of the visual field (LVF) are initially projected to the right cerebral hemisphere, and stimuli shown in the right half (RVF) are sent to the left cerebral hemisphere. This anatomical feature has been taken as support for the argument that LVF-RVF differences are an index of asymmetric functioning of the two ccrebral hemispheres (for reviews see Bradshaw \& Nettleton, 1983; Bryden, 1982; Hellige, 1993). Thus, the repeated finding that words are recognized more casily in the RVF than in the LVF is considered a consequence of left-hemisphere dominance for language processing. Further evidence for this position is obtained by finding that individuals with left hand preference show a reduced RVF superiority for word recognition relative to persons with right hand preference (Kim, 1994; but see Brysbaert, 1994c, for a more cautious account).

The interpretation of LVF-RVF differences in word processing as an indication of laterality has not remained unchallenged, however. At least three alternative explanations of the RVF superiority have been proposed. The first considers the

Marc Brysbaert and Walter Schroyens, Department of Psychology, University of Leuven, Leuven, Belgium; Françoise Vitu, Laboratoire de Psychologie Expérimentale, Centre National de Recherche Scientifique Université René Descartes, Paris, France.

The collaboration between the University of Leuven, Belgium, and the Université René Descartes of Paris was made possible by the Nationaal Fonds voor Wetenschappelijk Onderzoek, a Tournesol project between France and the Flemish Community of Belgium, and a European Union Erasmus Studentship. The authors wish to thank Philip Bryden and two anonymous reviewers for helpful comments on an earlier draft.

Correspondence concerning this article should be addressed to Marc Brysbaert, Department of Psychology, University of Leuven, B-3000 Leuven, Belgium.
RVF superiarity for word processing to be a consequence of the word beginning being more informative than the word end. This implies that a word presented to the right of the fixation location has its most informative part nearer to the line of sight than a word presented left of the fixation location (e.g., Kirsner \& Schwarz, 1986). Given that visual acuity drops steeply away from the fixation location (Anstis, 1974), such an arrangement favors the RVF for purcly perceptual reasons. Laterality researchers have argued against this perceptual hypothesis by showing that the LVF-RVF difference is not influenced by the information distribution within words (e.g., Bryden, 1986; Bryden, Mondor, Loken, Ingleton, \& Bergstrom, 1990; Brysbaert \& d'Ydewalle, 1990b; Eviatar \& Zaidel, 1991). Thus, Bryden et al. (1990) did not find a difference in VHF asymmetry for words that could be completed more easily on the basis of the last letters than on the basis of the first letters.

A second alternative explanation attributes the RVF superiority for word recognition to the use of languages rcad from left to right. The reading habits associated with these languages make it more easy to process a word right of fixation than a word left of fixation; and indeed the first experiments with languages read from right to left revealed a reversed VHF asymmetry (e.g., Mishkin \& Forgays, 1952; Orbach, 1952). However, subsequent and better controlled studies using native speakers reported RVF advantages both for languages read leftward and for languages read vertically (for reviews, see Faust, Kravetz, \& Babkoff, 1993; Malamed \& Zaidel, 1993).

A final alternative interpretation of the RVF advantage for word recognition assigns it to (attentional) scanning factors (e.g., Efron, 1990; Heron, 1957). It is assumed that for verbal stimuli the RVF is scanned before the LVF, which because of stimulus decay results in a RVF advantage. The problem with the scanning hypothesis, however, is that so far no one has explained why in word processing the RVF is scanned before 
the LVF and why this sequence changes for different kinds of stimuli (e.g., why the RVF is scanned first for digit words and second for bar graphs representing digits; Boles, 1986). In addition, Kim and Levine (1991) showed that although attentional factors accounted for about half of the interindividual variance in VHF asymmetries, there still was a significant additional effect of cerebral asymmetry (see also Brysbaert, 1994a). On the other hand, Mondor and Bryden (1992) showed that a significant 55-ms RVF advantage in a lexical decision task could be reduced to a nonsignificant 28-ms RVF advantage if a valid attentional cue was given $50 \mathrm{~ms}$ prior to the stimulus onset (but see Hardyck, Chiarello, Dronkers, \& Simpson, 1985).

Other studies have tried to validate the laterality account by looking at VHF asymmetries for different kinds of words. Experiments with split-brain patients (i.e., individuals in whom the commissures have been sectioned to treat epilepsy) had shown that the isolated right hemisphere contains a limited capacity for word comprehension (e.g., Zaidel, 1983). Thus, it was expected that the RVF superiority could differ as a function of word frequency, imageability, concreteness, emotionality, syntactic role, or word length. On the whole, the results have been negative for word frequency, imageability, concreteness, and emotionality. Low-frequency words do not lead to a larger RVF superiority than high-frequency words (e.g., Brysbaert \& d'Ydewalle, 1990b; Koenig, Wetzcl, \& Caramazza, 1992; McMullen \& Bryden, 1987; Mohr, Pulvermüller, \& Zaidel, 1994). Highly imageable words induce the same RVF advantage as words with low imageability (Boles, 1983; Hernandez, Nieto, \& Barroso, 1992; McMullen \& Bryden, 1987). Abstract words do not differ from concrete words (Boles, 1983; Eviatar, Menn, \& Zaidel, 1990), and emotional words give rise to the same VHF asymmetry as neutral words (Eviatar \& Zaidel, 1991).

On the other hand, there is some evidence that the RVF advantage is larger for function words than for content words (Bradley \& Garrett, 1983; Chiarello \& Nuding, 1987; Mohr et al., 1994), and virtually all findings point to an increasing RVF advantage with increasing word length (Bruyer \& Janlin, 1989; Brysbaert \& d'Ydewalle, 1990b; Bub \& Lewine, 1988; Ellis, Young, \& Anderson, 1988; Eviatar \& Zaidel, 1991; Young \& Ellis, 1985; but see Bruyer \& Ducarme, 1990). The latter is due to the fact that the LVF score drops more stecply as a function of word length than the RVF score. Some authors (e.g., Young \& Ellis, 1985) have interpreted this finding as evidence for two different modes of word processing in the left and the right cerebral hemisphere, whereas others (e.g., Schwartz, Montagner, \& Kirsner, 1987) saw it as evidence for the importance of visual acuity in the emergence of VHF asymmetries (see the pcrceptual hypothesis above).

In sum, laterality research has shown that parafoveally presented words are more easily recognized if they are presented to the right of the fixation location than if they are presented to the left of the fixation location. This is a quite robust phenomenon that generalizes across different kinds of words with different information values of beginning and end, and across languages with different reading directions. The predominant interpretation of the RVF word advantage is that it is due to structural characteristics of the visual pathways and the cerebral cortex, although possible additional effects of reading habits and attention allocation have been acknowlcdged (c.g., Bryden, 1986; Bryden \& Mondor, 1991; Hellige, 1986).

\section{The Optimal Viewing Position Effect in Foveal Word Recognition}

In VHF expcriments words are usually presented in parafoveal vision, with the nearest letter at a distance of minimally one degree of visual angle from the fixation location. Under normal reading conditions, one degree of visual angle agrees with three to four letter spaces (Rayner \& Pollatsek, 1989, p. 119). The precaution of parafoveal presentation is taken because latcrality researchers fear that foveal presentation of a word may lead to bilateral projection, either because of small eye movements or because the fovea itself is bilaterally representcd in the visual cortex (see e.g., McKeever, 1986; Young, 1982). Recent findings on the optimal viewing position (OVP) effect in foveal word recognition, however, suggest that this concern may be incorrect.

In the early 1980s O'Regan and colleagues discovered that the efficiency of foveal word recognition depends on the letter fixated within the word (Nazir, O'Regan, \& Jacobs, 1991; O'Regan, 1981; O'Regan \& Jacobs, 1992; O'Regan, LévySchoen, Pynte, \& Brugaillère, 1984). They found that word processing was optimal when observers were allowed to fixate between the first and the middle letter of the words. This was true for word lengths ranging from 5 to 11 letters. Response latencies increased and accuracy decreased if observers were forced to look at the extremes of words, and morc so when they were forced to look at the end than when they were forced to look at the beginning.

O'Regan and colleagues ascribed this pattern of results to a combination of three factors. First, due to the decrease of visual acuity outside the center of fixation (e.g., Anstis, 1974), recognition is more difficult for words presented away from the fixation location. This is even true for distances of less than one degree; that is, for stimuli displayed well within the foveal area. If the decrease of visual acuity were the only significant factor, the OVP would lie in the middle of a word and processing time would be a perfect $U$-shaped curve of the letter initially fixated (unless one accepts that the decrease of acuity is smaller in the RVF than in the LVF; Nazir et al., 1991). The faster processing of a word after fixation on the first half than after fixation on the last half was further explained by two additional factors, namely the fact that in the language studied (French) words are read from left to right, and the fact that most words can more easily be gucssed from their first letters than from thcir last letters. These two linguistic factors lead to the so-called word-beginning superiority effect.

The analogies between the explanation of the OVP effect and the alternative cxplanations of the VHF asymmetry are obvious. However, subscquent research has not confirmed O'Regan's interpretation of the OVP effect entirely. First, there is little evidence that words in a language read from left to right are also processed in a left-to-right manner. This is quite convincingly shown in a study by Radeau, Morais, Mousty, Saerens, and Bertelson (1992), who looked at the 
same language as O'Regan (i.e., French). Radeau et al. examined the time course of lexical access in written-word recognition by focusing on the uniqueness point (UP) effect. In earlier studies (Radeau \& Morais, 1990; Radeau, Mousty, \& Bertelson, 1989), they had shown that in spoken-word recognition, the recognition time of a word depended strongly on the position of its UP; that is, the point at which the word can bc distinguished from other words that begin with the same letters. Words with an early UP (e.g., aptitude) were recognized more rapidly than words with a laté UP (e.g., machinerie). In their study on printed word recognition, they replicated the UP effect with an incremental presentation of the word letters, but not with the normal presentation of the entire word. The incremental presentation situation consisted of progressively displaying the letters of a word on the screen, starting from the left, with each new letter coming into position at a speed designed to match the duration of the spoken word delivery. For example, the word spaghetti would involve the successive displays $s$, sp, spa, spag, spagh, spaghe, spaghet, spaghett, and spaghetti, at approximately the same rate as the word is commonly pronounced. The finding that the UP effect is present in spoken word recognition and in the incremental presentation situation, but not in the normal simultaneous presentation situation, strongly suggests that printed French words are not processed in left-to-right serial order, but that all letters are processed in parallel. Further evidence against the reading habit hypothesis comes from a study on the OVP effect in Arabic words, which are read from right to left (Farid \& Grainger, in press). These words do not give rise to an OVP shift to the right half of the words, but a much smaller shift toward a symmetric function.

Holmes and O'Regan (1987) tried to manipulate the information distribution within a word and looked at the influence on the OVP effect. They selected in the French dictionary two groups of 10 words: One group of words had the property of being uniquely defined by their first six letters (e.g., perquisition, attroupement); the other group was uniquely determined by the last six letters (e.g., circonspecte, interrogatif). Both groups of words were matched pairwise for length $(10-12$ letters) and for frequency. The task was semantic judgment: The test word appeared as the first word of a short phrase that could make sense or not. Oculomotor behavior was measured as a function of the imposed position where the eyes started fixating in the word. The main finding was that although the information distribution had some effect on the OVP pattern, it did not reverse the phenomenon: No word-end superiority effect was present for the words that were uniquely determined by their last letters. This seems to indicate that the wordbeginning superiority effect is not completely due to the fact that words on the average can be guessed better after knowledge of the first letters than after knowledge of the final letters. Similar results were reported by Farid and Grainger (in press) for prefixed and suffixed French words, together with the intriguing finding that the information distribution within a word had more effect in Arabic than in French.

The insensitivity of the word-beginning superiority effect to manipulations of reading habits and the informativeness of word beginnings and ends made Brysbaert (1994b) wonder whether the asymmetry of the OVP effect, just like the RVF advantage, could be (partially) explained by hemispheric specialization (see also Brysbaert \& d'Ydewalle, 1988). Individuals were diagnosed as left-hemisphere or right-hemisphere dominant for visual word processing on the basis of three VHF tasks: word naming, object naming, and clock-face reading. The first task was included for its obvious similarity with the OVP manipulation. The second task was added to ensure that the RVF superiority for word naming was not due to reading habits (i.e., observers had to name line drawings of five common objects that were symmetric around the vertical axis). The clock-face reading task, finally, was intended to draw upon processes of the nondominant cerebral hemisphere and was expected to yield VHF superiorities opposite to those of the first two tests. It was included to guarantee that the VHF superiorities in the first tests were not due to attentional imbalances.

On the basis of the three tests, 9 participants were diagnosed as left-hemisphere dominant and 9 other participants as right-hemisphere dominant. These individuals then named foveally presented words after fixation on different letters. The predictions of the hemispheric specialization hypothesis were confirmed: Observers with left-hemisphere dominance profited more from fixations on the beginning of a word than observers with right-hemisphere dominance, whereas the reverse was true for fixations on the end of a word. Thus, left-hemisphere dominant participants had a significantly larger word-beginning superiority effect than right-hemisphere dominant participants. This was already shown to be true for naming three-letter words that subtended a visual angle of less than one degree.

The findings of Brysbaert (1994b) suggest that there is no real difference between foveal and parafoveal word processing and that cerebral asymmetry is an important factor in the explanation of both the RVF advantage in parafoveal word recognition and the OVP effect in foveal word recognition. This adds further support to the growing body of doubts about the bilateral cerebral representation of foveal vision in humans (reviewed by Brysbaert, 1994b; see also Sugishita, Hamilton, Sakuma, \& Hemmi, 1994, for additional recent evidence).

The experiments described below were devised to further investigate the relationship between the RVF advantage and the OVP effect. They are based on the OVP paradigm. Observers are asked to look at a fixation location, and words are presented in such a way that the center of the word is shifted to one or the other side. The major difference from the classic OVP paradigm is that words can be shifted so much that the participants no longer fixate on a letter of the word, but either on some letter spaces in front of the word or on those behind the word. We will call the new paradigm the extended OVP paradigm (EOVP). It combines the classic OVP paradigm and the usual VHF paradigm (with parafoveal word presentation). By presenting words randomly in foveal and parafoveal vision, a direct comparison between both presentation conditions can be made. In line with several previous OVP experiments (e.g., Nazir et al., 1991; Nazir, Heller, \& Sussmann, 1992), a perceptual identification task was used, with identification accuracy as the dependent variable.

In the first cxperiment, the EOVP effect was established for five-letter words over a relatively broad range of presentation 


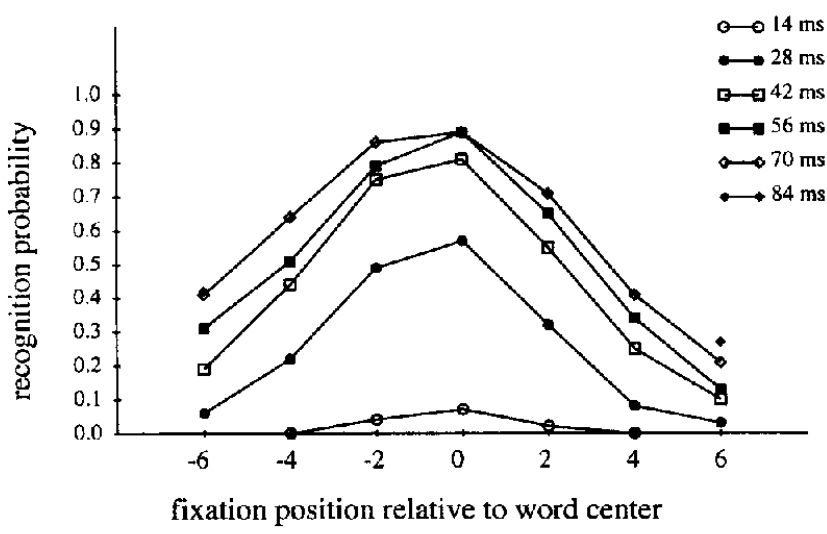

Figure 1. Word recognition probability as a function of fixation position relative to the word center and presentation duration: Experiment 1.

times. In Experiment 2, the range of durations was limited and the effect of word length was investigated. Finally, in Experiment 3 we looked at the effect of different information values for word beginning and word end.

\section{Experiment 1}

In Experiment 1, we examined the EOVP effect for French words of five letters. This was done by shifting the word relative to the fixation position, so that the observer either looked at the center of the word, at the first or the last letter of the word, or two and four letter positions in front of and behind the word. In addition, presentation time was varied between 14 and $84 \mathrm{~ms}$. The dependent variable was the percentage of words correctly identified.

\section{Method}

Participants. Participants were 35 students from the Université René Descartes and the Université Catholique (Paris, France). All were native French speakers, had normal or corrected-to-normal vision, and were unaware of the research hypothesis. Twenty-seven participants were female. Participation in the experiment was on a voluntary basis.

Stimuli. Stimuli were 280 French five-letter words with mean frequency of 78 per million (Trésor de la langue française, 1971). They were divided in 35 lists of eight words matched for frequency. Thirty-five stimulus lists were needed because of the orthogonal variation of word position (seven levels) and presentation duration (five levels). Word position was manipulated so that observers looked either four letter positions in front of the word, two letter positions in front of the word, on the first letter of the word, on the middle letter of the word, on the last letter of the word, two letter positions behind the word, or four letter positions behind the word. Presentation times varied between 14 and $84 \mathrm{~ms}$ (i.e., multiples of the $70-\mathrm{Hz}$ refresh rate of the CRT monitor). Presentation times of $28,42,56$, and $70 \mathrm{~ms}$ were used for all word positions. The presentation time of $14 \mathrm{~ms}$ was not used for the word positions in the extreme parafoveal conditions (i.e., four letter positions in front of and behind the word) because it was expected that words would not be recognizable for these particular pairs of duration and location. Instead, they were replaced by a $84-\mathrm{ms}$ presentation condition, making a total of 35 different locationduration combinations. The lists of words were distributed over the conditions according to a Latin square so that each list was seen in each condition once (hence 35 participants). After the assignment of presentation conditions to the individual words, the list was permuted at random for each participant (Brysbaert, 1991). There were no orthographic, semantic, or syntactic constraints for the inclusion of words in the lists (e.g., verb forms could be included, together with adjectives and nouns). Words were presented in MS-DOS text mode using the default font and $80 \times 25$ character spacing.

Procedure. Stimuli were presented on a CRT monitor connected to an IBM compatible microcomputer. A character space subtended one third of a centimeter horizontally, so that there were three character spaces per degree of visual angle at a viewing distance of $57 \mathrm{~cm}$. At the beginning of a trial two vertically aligned lines appeared on the center of the screen with a gap between them. Observers were asked to fixate the gap. Five hundred milliseconds later, a word was shown on the text line that coincided with the gap between the two vertical lines. Words could be presented on any of the seven positions described above and for all possible durations. Immediately after the stimulus time had elapsed, the word was replaced by a mask, which consisted of the ASCII Code 178 repeated five times and aligned horizontally. The fixation lines remained visible throughout the total presentation time of target and mask. The mask stayed on the screen for $800 \mathrm{~ms}$, after which the screen was blanked and a prompt appeared at the bottom of the screen. Participants had to type in their response. They were encouraged to guess if they were not sure about the correct answer. The 280 test trials were preceded by 20 practice trials. Each participant was seen individually in a quiet room. The experiment lasted about $1 \mathrm{hr}$.

\section{Results}

Figure 1 displays the percentage of correct word identifications as a function of presentation location and stimulus duration (see also the left part of Table 1 for the exact values).

Table 1

Recognition Rates for the Duration/Position Conditions of Experiment 1, Lambda Indices, and Estimates of the Unknown Parameters in the Nonlinear Regression Analysis

\begin{tabular}{|c|c|c|c|c|c|c|c|c|c|c|c|c|c|c|c|c|c|c|c|}
\hline \multirow[b]{2}{*}{ Duration } & \multirow[b]{2}{*}{-6} & \multirow[b]{2}{*}{-4} & \multirow[b]{2}{*}{-2} & \multirow[b]{2}{*}{0} & \multirow[b]{2}{*}{2} & \multirow[b]{2}{*}{4} & \multirow[b]{2}{*}{6} & \multicolumn{2}{|c|}{$\Lambda_{(-2 i+2)}$} & \multicolumn{2}{|c|}{$\Lambda_{(-4 /+4)}$} & \multicolumn{2}{|c|}{$\Lambda_{(-6 ;+6)}$} & \multicolumn{2}{|c|}{ Prob } & \multicolumn{2}{|c|}{ OVP } & \multicolumn{2}{|c|}{$S D$} \\
\hline & & & & & & & & Est. & $5 \%$ & Est. & $5 \%$ & Est. & $5 \%$ & Est. & $5 \%$ & Est. & $5 \%$ & Est. & $5 \%$ \\
\hline $14 \mathrm{~ms}$ & - & .00 & .04 & .07 & .02 & .00 & - & .90 & 1.08 & - & & - & & .07 & .01 & -.37 & .13 & 2.06 & .17 \\
\hline $28 \mathrm{~ms}$ & .06 & .22 & .49 & .57 & .32 & .08 & .03 & .71 & .35 & 1.18 & .52 & .85 & .87 & .58 & .03 & -.63 & .14 & 3.40 & .19 \\
\hline $42 \mathrm{~ms}$ & .19 & .44 & .75 & .81 & .55 & .25 & .10 & .92 & .37 & .82 & .36 & .72 & .50 & .82 & .03 & -.67 & .15 & 4.32 & .22 \\
\hline $56 \mathrm{~ms}$ & .31 & .51 & .79 & .89 & .65 & .34 & .13 & .72 & .38 & .71 & .35 & 1.13 & .44 & .87 & .07 & -.64 & .32 & 4.87 & .50 \\
\hline $70 \mathrm{~ms}$ & .41 & .64 & .86 & .89 & .71 & .41 & .21 & .88 & .43 & .92 & .35 & .94 & .38 & .90 & .03 & -.85 & .18 & 5.63 & .31 \\
\hline $84 \mathrm{~ms}$ & .42 & - & - & - & - & - & .27 & -- & & - & & .69 & .36 & & & & & & \\
\hline
\end{tabular}

Note. Prob $=$ probability of word recognition at the optimal viewing position (OVP); Est. = estimated; $5 \%=5 \%$ confidence interval. Dashes indicate that these conditions were not used. 
Analyses of variance (ANOVAs) are not needed to see that both variables had a profound effect: Words had higher chances of being recognized if they were centered around the line of sight and if they were presented for a longer period of time. Furthermore, the functions relating recognition rate to stimulus position are not symmetric: Chances of recognizing the word are higher for fixations to the left of the word center (i.e., on the first half of the word and in front of the word) than for fixations to the right of the word center (i.e., on the last half of the word and behind the word). This becomes especially clear when the lambda index is calculated for the different eccentricities. The lambda index is a common laterality index of accuracy (Brysbaert \& d'Y dewalle, 1990a; Sprott \& Bryden, 1983 ) and is obtained by applying the following equation to the values of Table 1 :

$$
\Lambda=\ln \left(P_{\text {correct(RVF) }} / P_{\text {wrong(RVF })}\right)-\ln \left(P_{\text {correct(LVF })} / P_{\text {wrong(LVF })}\right)
$$

Three lambda indices can be calculated for the presentation times ranging from 28 to $70 \mathrm{~ms}$ : one for the difference at positions 2 and -2 , one for positions 4 and -4 , and one for positions 6 and -6 . Two more indices can be calculated: one for positions 2 and -2 in the $14-m s$ presentation condition, and another for positions 6 and -6 in the $84-\mathrm{ms}$ presentation condition. All values are tabulated in the middle part of Table 1 , together with the $5 \%$ confidence intervals. ${ }^{1}$ As can be seen, all lambda indices fall within the same range. On the average, lambda was .83 for positions $-2 /+2, .91$ for positions $-4 /+4$, and .87 for positions $-6 /+6$.

The lack of a reliable effect due to presentation time and stimulus position can further be demonstrated by calculating a $4 \times 3$ ANOVA with repeated measures on the lambda indices of the individual participants for the presentation times of 28 , 42,56 , and $70 \mathrm{~ms}$. This analysis failed to return significant effects due to duration $(F<1, M S E=1.55)$ and position $(F<1, M S E=1.84)$. It should be noted, however, that the ANOVA was handicapped because there were only eight observations per cell per participant. This quite often required a correction factor of +0.2 if no word had been recognized and -.2 if all words had been recognized (these correction factors were chosen because they returned a value of $\ln (.2 / 7.8)=$ -3.66 when no word had been recognized and a value of $\ln (7.8 / .2)=+3.66$ when all words had been identificd) .

The reason the lambda indices are virtually the same for all cccentricities is that the identification probability as a function of stimulus location is quite well captured by a Gaussian distribution shifted to the left of the word center, as is shown in Figure 2. The curves of Figure 2 were obtained by nonlinear regression analyses (with the quasi-Newton and simplex algorithms; Statsoft, 1991), using the following equation:

$$
P_{\text {correct }}=\operatorname{prob} * \exp \{-\operatorname{sqr}[(\text { eyepos }-\mathrm{OVP}) / S D]\} \text {, }
$$

in which $P_{\text {correct }}$ stands for the percentage of correct identification (i.e., the values on the ordinate of Figures 1 and 2), cyepos for the deviation between the line of sight and the center of the word (i.e., the values on the abscissa of Figures 1 and 2), prob for the probability of word recognition at the OVP, and $S D$ for the standard deviation of the Gaussian distribution. The right

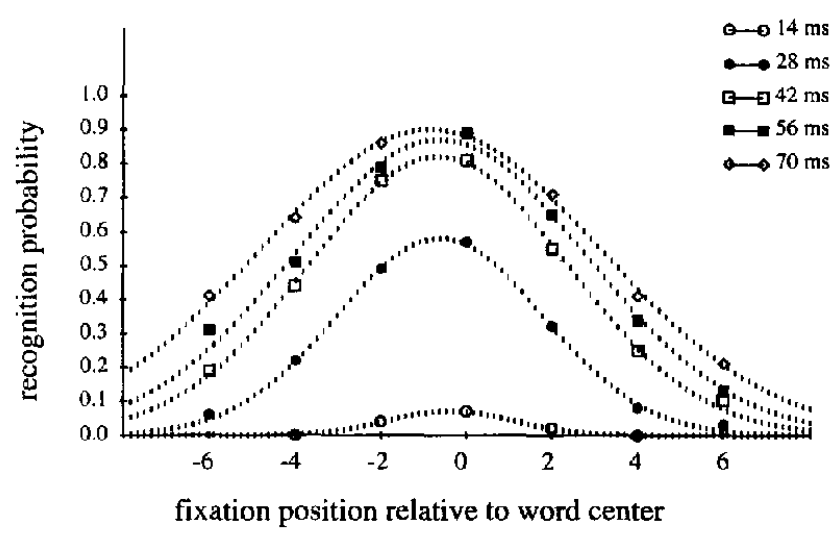

Figure 2. Word recognition probability as a function of fixation position and presentation duration (Experiment 1), together with the best fitting Gaussian curves (see Table 1).

part of Table 1 gives the estimates and the .05 confidence intervals for the three unknown variables: prob, OVP, and $S D$ (these values were not estimated for the $84-\mathrm{ms}$ presentation duration because there were only two data points there; see Figure 1).

Stimulus duration had a clear effect on prob (i.e., the height of the curve), and on $S D$ (the width of the curve), but not on OVP (the shift of the curve to the left), at least not for the three stimulus durations that are least susceptible to floor or ceiling effects (i.e., presentation times of 28,42 , and $56 \mathrm{~ms}$ ). The fact that all recognition rates fall on normal distributions that are shifted with the same amount to the left means that the laterality scores for the different positions and durations must be the same if they are properly corrected for the overall recognition rate.

\section{Discussion}

Given the similarities between the OVP effect and the RVF advantage for words, we hypothesized that both phenomena might be due to the same origins (see also Brysbaert, 1994b). Figures 1 and 2 show that this is indeed the case: Both the OVP effect and the VHF asymmetries at different eccentricities appear to be part of a more general EOVP curve that can be described as a Gaussian curve slightly (i.e., about two thirds of a letter) shifted to the left of the word center. There are no apparent discontinuities between foveal and parafoveal word recognition. In the next experiments we examined the effects of word length and information distribution within words on the EOVP curve.

\footnotetext{
${ }^{1}$ The standard deviation of the lambda index is obtained with the equation $S D=\operatorname{sqrt}\left(1 / N+_{\mathrm{RVF}}+1 / N-{ }_{\mathrm{RVF}}+1 / N+_{\mathrm{LVF}}+1 / N-_{\mathrm{LVF}}\right)$ in which $N+$ and $N-$ are the number of correct and incorrect identifications (Brysbaert \& d'Ydewalle, 1990b; Sprott \& Bryden, 1983). Because the equation assumes independence of observations, the calculated values of the present studies are likely to be slight underestimates (because not all observations came from different subjects). That is why the estimates are always given in parallel with analyses of variance based on repeated measures.
} 


\section{Experiment 2}

Experiment 1 showed that the recognition probability of five-letter words as a function of stimulus eccentricity is well described by a Gaussian curve shifted two thirds of a letter to the left of the center of the word. This raised the question of what happens for other word lengths. As indicated in the introduction, word length is the most consistent variable that affects the magnitude of the RVF advantage for words. It may therefore be worthwhile to check how this phenomenon can be accounted for within the framework of the EOVP effect. In addition, in Experiment 2 we tried to achieve better fixation control on the part of the observers and extended the findings from the French to the Dutch language (see also Brysbaert, 1994b; Brysbaert \& d'Ydewalle, 1988). If the OVP and the VHF effects are due to structural properties (i.e., drop of visual acuity outside the center of fixation and cerebral asymmetry) and to attentional factors due to the reading direction, they should be more or less the same for the two languages.

\section{Method}

Participants. Participants were 42 students from the University of Leuven, Belgium, who participated on a voluntary basis or to receive course credits. All were native Dutch speakers, had normal or corrected-to-normal vision, and were unaware of the research hypothesis. Eighteen participants were women.

Stimuli. Stimuli were three lists of 84 Dutch words with, respectively, three letters, five letters, and seven letters. Words within the lists were matched for frequency ( $M=11$ per million; Burnage, 1990). $A s$ in Experiment 1, apart from frequency and length there were no other constraints for inclusion of a word in a list. Each list was subdivided into 14 homogeneous sublists of six words each. Fourteen lists were needed because we had two durations ( $28 \mathrm{~ms}$ and $42 \mathrm{~ms}$ ) and seven possible stimulus positions. The positions were either the center of the word, the two letters around the center (i.e., positions -1 and +1 ), positions -3 and +3 , and positions -5 and +5 . These positions were preferred to those of Experiment 1 in order (a) to have three within-word fixations for the three-letter words and (b) to get a better estimate of the OVP near the word center. Distribution of the sublists over the conditions and randomization of the lists happened as in Experiment 1. Each sublist/condition pair was seen by 3 observers.

Procedure. The procedure was the same as in Experiment 1 except for one change. In order to ensure that the observers really fixated between the two vertical lines, after a random number of trials (geometric distribution with expected value of S, see Brysbaert, 1991), a random digit instead of a new stimulus word was presented in the fixation gap for $56 \mathrm{~ms}$, followed by a mask (ASCII 178). Participants had to name the digit (on these trials, there was no word). If they made a mistake they were warned by a tone. They were urged to try for $100 \%$ correct. Although there was no digit to be named on each trial, the strategy made the participants very alert to look at the fixation location on all trials. On the average, only one observer out of two missed one of the 51 or so digits. This procedure was preferred to eye fixation control with the use of an eye tracker, because this would have prevented a stimulus identification task (few people can type without moving their head).

Words were presented in blocks of the same length (counterbalanced according to a Latin square over the three observers of a particular sublist/condition pair). Observers were informed about the length of the words in an upcoming block. Masks had the same length as stimulus words and were obtained by aligning three, five, or seven instances of ASCII Code 178 horizontally.

\section{Results and Discussion}

Table 2 displays percentage correct word identification as a function of word length, stimulus presentation time, and stimulus location (see also Figure 3), together with the lambda indices and the least square estimates of prob, OVP, and $S D$ for the best fitting Gaussian curves. Several points are noteworthy.

First, when the equivalent conditions of Experiment 1 and 2 are compared, it appears that the Leuven students outperformed their Paris colleagues (i.e., higher values of prob and $S D$ ) despite the fact that the Dutch words were less frequent than the French words. Two factors may have contributed to this finding. First, brightness of the stimuli and illumination of the test room may not have been completely the same (different rooms were used, and there was a time interval of several months between Experiment 1 and 2). Second, a considerable number of French words, unlike Dutch words, contained accent marks, which may have restrained correct identification.

A second remarkable aspect of Table 2 compared with Table 1 is that despite the different recognition probabilities, the estimates of OVP for the five-letter words are exactly the same. This strengthens the argument made in the Results

Table 2

Recognition Rates for the Duration/Position Conditions of Experiment 2, Lambda Indices, and Estimates of the Unknown Parameters in the Nonlinear Regression Analysis

\begin{tabular}{|c|c|c|c|c|c|c|c|c|c|c|c|c|c|c|c|c|c|c|c|}
\hline \multirow[b]{2}{*}{ Duration } & \multirow[b]{2}{*}{-5} & \multirow[b]{2}{*}{-3} & \multirow[b]{2}{*}{-1} & \multirow[b]{2}{*}{0} & \multirow[b]{2}{*}{1} & \multirow[b]{2}{*}{3} & \multirow[b]{2}{*}{5} & \multicolumn{2}{|c|}{$\Lambda_{(-1 /+1)}$} & \multicolumn{2}{|c|}{$\Lambda_{(-3 /+3)}$} & \multicolumn{2}{|c|}{$\Lambda_{(-5 i+5)}$} & \multicolumn{2}{|c|}{ Prob } & \multicolumn{2}{|c|}{ OVP } & \multicolumn{2}{|c|}{$S D$} \\
\hline & & & & & & & & Est. & $5 \%$ & Est. & $5 \%$ & Est. & $5 \%$ & Est. & $5 \%$ & Est. & $5 \%$ & Est. & $5 \%$ \\
\hline \multicolumn{20}{|c|}{ Three-letter words } \\
\hline $28 \mathrm{~ms}$ & .22 & .54 & .79 & .85 & .80 & .46 & .11 & -.05 & .44 & .30 & .36 & .84 & .51 & .85 & .06 & -.23 & .26 & 4.00 & .43 \\
\hline $42 \mathrm{~ms}$ & .39 & .69 & .92 & .91 & .88 & .57 & .29 & .40 & .60 & .53 & .37 & .48 & .38 & .93 & .03 & -.36 & .14 & 4.93 & .26 \\
\hline \multicolumn{20}{|c|}{ Five-letter words } \\
\hline $28 \mathrm{~ms}$ & .25 & .59 & .82 & .83 & .75 & .32 & .08 & .40 & .44 & 1.12 & .37 & 1.43 & .56 & .86 & .06 & -.66 & .24 & 3.82 & .39 \\
\hline $\begin{array}{l}42 \mathrm{~ms} \\
\text { Seven-letter wo }\end{array}$ & .41 & .70 & .91 & .88 & .85 & .49 & .21 & .54 & .57 & .89 & .37 & .97 & .40 & .92 & .04 & -.65 & .22 & 4.72 & .42 \\
\hline $28 \mathrm{~ms}$ & \multicolumn{19}{|c|}{ Seven-letter words } \\
\hline $42 \mathrm{~ms}$ & .40 & .74 & .89 & .87 & .80 & .42 & .09 & $\begin{array}{l}.33 \\
.68\end{array}$ & $\begin{array}{l}.42 \\
.51\end{array}$ & $\begin{array}{l}1.24 \\
1.36\end{array}$ & $\begin{array}{l}.37 \\
.38\end{array}$ & $\begin{array}{l}1.41 \\
1.73\end{array}$ & $\begin{array}{l}.53 \\
.48\end{array}$ & $\begin{array}{l}.83 \\
.92\end{array}$ & $\begin{array}{l}.07 \\
.06\end{array}$ & $\begin{array}{l}-.76 \\
-.92\end{array}$ & $\begin{array}{l}.29 \\
.28\end{array}$ & $\begin{array}{l}3.98 \\
4.40\end{array}$ & $\begin{array}{l}.50 \\
.49\end{array}$ \\
\hline
\end{tabular}

Note. Prob = probability of word recognition at the optimal viewing position (OVP); Est. = estimated; $5 \%=5 \%$ confidence interval. 


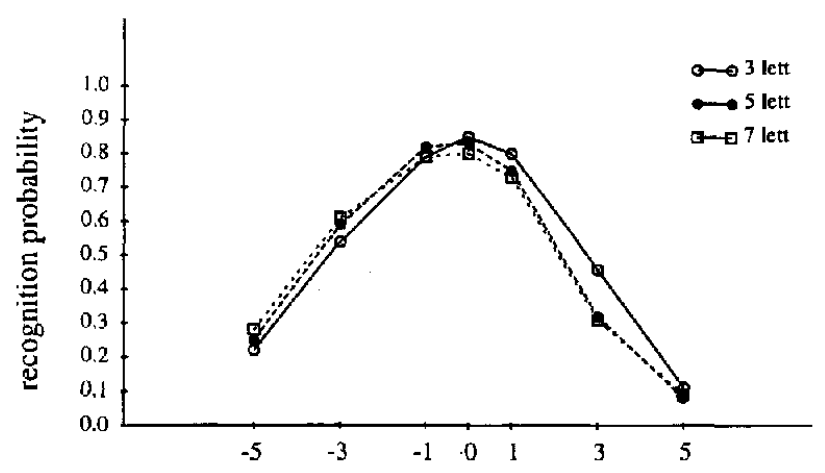

fixation position relative to word center

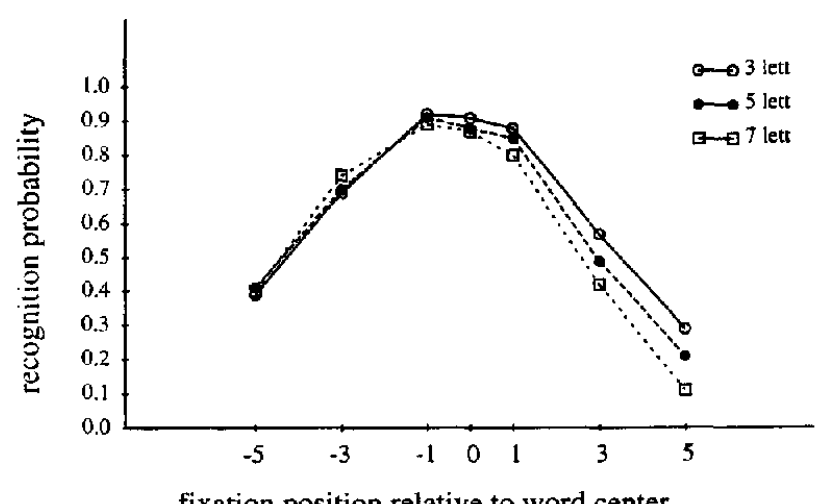

Figure 3. Word recognition probability as a function of fixation position relative to the word center, word length, and presentation duration in Experiment 2. Top: $28-\mathrm{ms}$ presentation time. Bottom: 42-ms presentation time. lett $=$ letters.

section of Experiment 1 that the asymmetry of the EOVP curve is uninfluenced by overall recognition rate. Moreover, it also indicates that the asymmetry is language independent (at least for languages read in the same direction). This either means that Dutch and French share the same properties underlying the shift of the Gaussian curve to the left, or that the shift is due to nonlinguistic factors (see Experiment 3).

A third important characteristic in Table 2 and Figure 3 is that the differences between the EOVP curves due to word length are entirely situated in the value of the OVP. The OVP shifts more to the word beginning for long words than for short words. When the .05 confidence intervals are taken into account, there are no reliable effects of word length for the prob and the $S D$ parameter. This means that three-letter words are not more difficult to identify than seven-letter words of the same frequency if the entire curve is considered. Only when the fixation conditions are restricted to the OVP of the word and the letter positions to the right of the OVP does there seem to be a difference in favor of short words. Fixations imposed to the left of the OVP give rise to an opposite pattern of results (see Figure 3).

An ANOVA with word length and eccentricity as repeated measures calculated on the lambda indices (with a correction factor of +.3 if no word was recognized in a cell and -.3 if all 12 words had been recognized) confirmed that the VHF asymmetry increased for longer word lengths: $\Lambda=.44, .96$, and 1.26 for words of three, five, and seven letters, respectively, $F(2,82)=19.71, M S E=1.10, p<.01$; all lengths were significantly different from one another according to the Newman-Keuls test. However, the ANOVA also indicated a significant effect of stimulus eccentricity, $F(2,82)=20.98$, $M S E=1.25, p<.01$, due to the fact that $\Lambda$ was significantly smaller at positions $-1 /+1(\Lambda=.37)$ than at positions $-3 /+3$ $(\Lambda=1.09)$ and $-5 /+5(\Lambda=1.21)$. Figure 4 displays the effects of word length and eccentricity. The interaction between length and eccentricity was not reliable, $F(4,164)=1.23, M S E$ $=0.97$, although Figure 4 shows that the difference between the three-letter words on the one hand and the five- and seven-letter words on the other hand, tended to be more pronounced for the positions $-3 /+3$ and $-5 /+5$ than for the position $-1 /+1$. To ensure that the eccentricity effect was not an artifact of the lambda index itself, we looked at the residual scores after the nonlinear regression analysis of the EOVP curve and found, as expected, that the recognition rate at position -1 in all but one case had been overestimated and that the recognition rate at position +1 had always been underestimated. The amount of over- and underestimation increased for increasing word lengths.

The lower lambda values for position $-1 /+1$ than for the other two positions agrees with the conclusion reached by Brysbaert (1994b) that interhemispheric transfer is not an all-or-none effect but that the processing cost depends on the number of letters that need to be transferred. At position $-1 /+1$ only the three-letter words were completely presented in one or the other VHF (i.e., observers fixated on the first or the last letter of the word). For the five- and seven-letter words, this did not happen until eccentricity $-3 /+3$ was reached. Although the pattern is not fully supported by the data, one might tentatively conclude that the lambda index increases as long as the complete word is not presented laterally (i.e., as long as the observer does not fixate on or

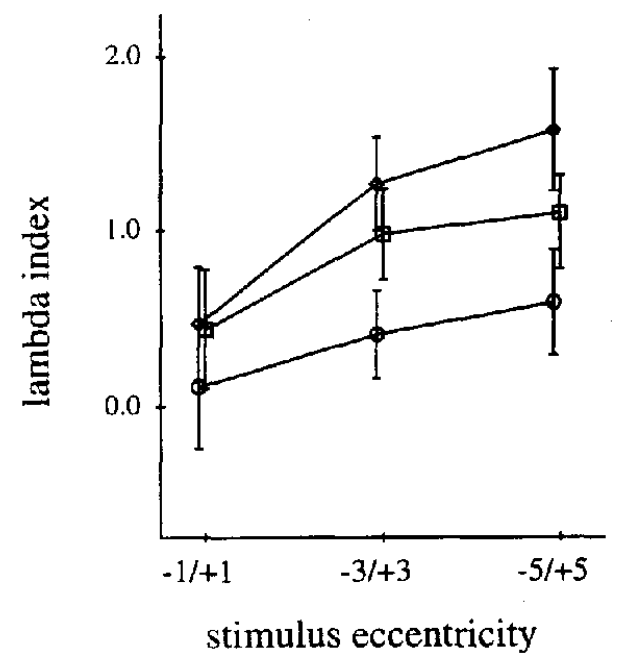

Figure 4. Values of the lambda index and $5 \%$ confidence intervals as a function of word length (circles $=$ three-letter words, squares $=$ fiveletter words, and diamonds = seven-letter words) and stimulus eccentricity (Experiment 2). 
slightly beyond the outer letter positions), but that afterward the value remains fairly constant.

\section{Experiment 3}

An interesting finding of Experiment 2 was that the OVP shift for five-letter words was virtually identical for French and Dutch. This raises the question whether the shift is due to language properties that are the same for Dutch and French or whether it is caused by processing characteristics that are language independent. In particular, one might wonder whether the EOVP curve is influenced by the informativeness of word beginning and end (suggesting that on average these values match in Dutch and French) or not. The question of the information distribution within a word is also important for the apparent contradiction between the OVP and the VHF experiments discussed in the introduction. Working on the OVP effect, both Holmes and O'Regan (1987) and Farid and Grainger (in press) obtained a small effect due to the information value of the word halves, whereas Bryden et al. (1990) failed to find an effect on VHF asymmetries. Experiment 3 directly compares parafoveal and foveal word recognition for Dutch five-letter words that are highly predictable on the basis of the first trigram or on the basis of the last trigram. Presentation time was fixed at $28 \mathrm{~ms}$.

\section{Method}

Participants. Thirty-five participants of Experiment 2 also participated in Experiment 3. This was possible because they had not yet been debriefed about the purpose of the experiments.

Stimuli. Stimuli were 56 Dutch five-letter words (different from the words used in Experiment 2). Selection was achieved in two steps. First, on the basis of trigram frequencies, words were chosen that had (a) a unique trigram at the beginning and a redundant trigram at the end (note that the middle letter was part of both trigrams), or (b) a redundant trigram at the start and a unique trigram at the end. This gave a total of 49 words with a unique beginning and 44 word with a unique end (seven words had been discarded because their frequencies were too high in comparison with the other words). These 93 words were then administered to 40 students from the University of Leuven (different from the ones who participated in the current experiments), 20 of whom saw the first three letters of the words and 20 the last three letters. Participants were asked to complete the trigrams in order to get an existing five-letter word. On the basis of these data, 28 words were selected that had on the average $84 \%$ chance of being successfully completed on the basis of the first trigram compared with $9 \%$ on the basis of the last trigram, and 28 other words that had an $8 \%$ chance of being guessed on the basis of the first trigram and $71 \%$ on the basis of the last trigram. Mean frequency of the lists (Burnage, 1990) was 13 per million for the words with a unique beginning and 16 per million for the words with a unique end $(F<1)$.

Procedure. The procedure was the same as in Experiments 1 and 2, except for the following three changes. First, the positions of Experiment 1 (i.e., $-6,-4,-2,0,2,4$, and 6 ) were used rather than those of Experiment 2. Second, the fixation control procedure with the masked digits of Experiment 2 was repeated. Only four subjects missed one digit on a total of 11 or so presentations. Third, because of the limited number of stimuli and the absence of interaction effects due to presentation duration in the previous experiments, only the $28-\mathrm{ms}$ viewing condition was used.

\section{Results and Discussion}

Figure 5 displays percentage correct word identification as a function of information distribution and word position. An ANOVA on these percentages with these two variables as repeated measures revealed no main effect due to information distribution $(F<1, M S E=0.030)$, a significant main effect of stimulus position, $F(6,204)=169.82, M S E=0.041, p<.01$, and a significant interaction, $F(6,204)=4.52, M S E=0.036$, $p<.01$. Planned comparisons showed that the information curves differed significantly $(p<.01)$ at positions -2 and +2 only; the difference at position -4 was not significant, $F(1,34)=$ 2.50. This confirms the discrepancy of the effects of information asymmetry between foveal (OVP) and parafoveal (VHF) word identification (see the introduction of Experiment 3).

Nonlinear regression analyses returned a Gaussian curve with the values prob $=.91( \pm .04), \mathrm{OVP}=-.87( \pm .13)$, and $S D=3.84( \pm .21)$ for the words with an informative beginning, and the values prob $=.86( \pm .11), \mathrm{OVP}=-.31( \pm .40)$, and $S D$ $=3.95( \pm .61)$ for the words with an informative end. These analyses confirm that although the informativeness variable had some effect, it did not suffice to push the mode of the distribution to the right half of the words. The same conclusion was reached after calculation of the lambda indices that never became negative. They amounted to $1.54( \pm .56), 1.37( \pm .54)$, and $1.04( \pm .92)$ for the increasing eccentricities of the words with an informative beginning and to $0.04( \pm .50), 0.88( \pm .54)$, and $1.28( \pm 1.04)$ for the words with a unique end. It may be useful to remember that the information manipulation in the present experiment was quite stringent, with a ninefold increase of successful word completion after knowledge of the informative trigram than after knowledge of the redundant trigram.

\section{General Discussion}

Since the discovery of the OVP effect in the early 1980 s, it is becoming increasingly clear that foveal word recognition is restrained by characteristics of the visual system. In particular, the drop of acuity outside the center of the visual field and the

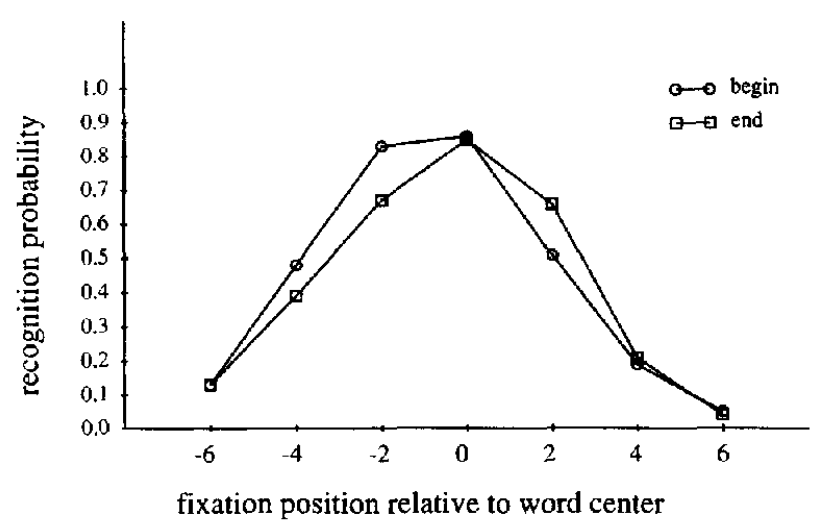

Figure 5. Probability of five-letter word recognition as a function of fixation position and informativeness of word beginning and word end (Experiment 3). 
left-right processing imbalance make a word easier to identify when it is fixated slightly to the left of the center than when it is fixated toward the extremes. The present studies extended this finding to parafoveal word recognition and showed that the OVP effect is part of a larger figure that can be described as a Gaussian curve with the mode shifted to the left of the word center (see Figures 1, 2, 3, and 5). The shift is a function of the word length but not of the presentation duration. Also the RVF advantage reported in laterality studies of visual word processing is part of this EOVP curve.

The most important conclusion from the EOVP effect for laterality researchers is that the difference between foveal and parafoveal word recognition is much smaller than generally assumed. In particular, the finding of an equivalent left-right asymmetry for foveally and parafoveally presented words was not predicted on the basis of current beliefs about the bilateral representation of foveal vision (e.g., Rayner \& Pollatsek, 1989, p. 21). This indicates either that there is no bilateral cerebral representation of central vision or that the RVF advantage for words is unrelated to cerebral dominance. As for the latter possibility, it may be worrisome that researchers of the OVP phenomenon typically have denied the laterality account of their findings (e.g., Farid \& Grainger, in press; Nazir et al., 1991, 1992; O'Regan et al., 1984; O'Regan \& Jacobs, 1992). On the other hand, an extensive review of the literature (Brysbaert 1994b; see also Sugishita et al., 1994) showed that the evidence for bilateral representation of foveal vision is much weaker than generally thought and that interhemispheric transfer in visual perception may be more common than accepted nowadays. Furthermore, Brysbaert (1994b), using naming latencies, found significant positive correlations between the asymmetry of the OVP effect and previously collected VHF differences for word naming and object naming, together with a negative correlation for clockface reading. This suggests that at present evidence is more in favor of foveal splitting than of a nonhemispheric account of the RVF advantage for words.

The fact that cerebral asymmetry is likely to underlie both the OVP effect and the RVF advantage for word processing does not prevent other factors from contributing to the left-right difference, as can be concluded from the following findings. First, there is a shift in the OVP to the right for languages read leftward, which points to an influence of reading habits (Farid \& Grainger, in press). This shift is not large enough to have the OVP situated in the right half of the words, which is in line with the RVF advantage for Hebrew and Arabic words (Faust et al., 1993; Malamed \& Zaidel, 1993). Second, the effect of hemispheric specialization is not strong enough to alter the word-beginning superiority of left-hemisphere dominant individuals to a word-end superiority for right-hemisphere dominant individuals (Brysbaert, 1994b). It only results in a shift toward a more symmetric function, so that at least part of the word-beginning superiority must be due to other, linguistic, factors. Third, in a VHF task with Dutch five-letter words administered to 71 individuals with mixed lateral preferences, only one returned a negative lambda index (Brysbaert, 1994c). This figure is too low given estimates of anomalous cerebral dominance in these individuals, and therefore must partly be due to linguistic or attentional factors. Finally, the information values of word begin- ning and word end do affect the EOVP curve and hence show that this variable is not without importance (although it should be noted that the effect is stronger in foveal vision than in parafoveal vision; see Figure 5).

In general, then, both the commonly found word-beginning superiority effect in foveal word recognition and the RVF advantage in parafoveal word recognition are likely to be due to the combincd effects of (a) rightward reading habits, (b) the frequently encountered greater informativeness of the first letters of a word, and (c) the high probability of lefthemisphere dominance for language processing. If so, the prediction follows that an equivalent shift of the OVP to the right half of the word and an equivalent LVF advantage will only be seen (a) in languages read from right to left, (b) with words that have an informative beginning, and (c) observers who are right dominant. This interpretation is compatible with current findings both on the OVP effect and on the VHF asymmetries in language processing (see the introduction).

From a pragmatic point of view, the parallel between foveal and parafoveal word presentation implies that researchers need not present their stimuli too far in the parafovea in order to obtain reliable VHF differences. The value of three degrees sometimes given is certainly too high. Both the present results and those of Brysbaert (1994b) indicate that, at least for words, very much the same results are obtained by comparing performance after fixation on the first letter of the word and fixation on the last letter of the word. Presenting words nearer to the fixation location has the advantage that it increases the ecological validity of the VHF task. Estimates of interhemispheric transmission load are lower, though not absent, for fixations on inner letters. Brysbaert (1994b) proposed that the transmission load may be a direct function of the number of letters that need to be transferred; an idea that is not in contradiction with the present findings (see Figure 4).

\section{References}

Anstis, S. M. (1974). A chart demonstrating variations in acuity with retinal position. Vision Research, 14, 589-592.

Boles, D. B. (1983). Dissociated imageability, concreteness, and familiarity in lateralized word recognition. Memory \& Cognition, 11, 511-519.

Boles, D. B. (1986). Hemispheric differences in the judgement of number. Neuropsychologia, 24, 511-519.

Bradley, D. C., \& Garrett, M. F. (1983). Hemisphere differences in the recognition of closed and open class words. Neuropsychologia, 21, 155-159.

Bradshaw, J. L., \& Nettleton, N. C. (1983). Human cerebral asymmety. Englewood Cliffs, NJ: Prentice-Hall.

Bruyer, R., \& Janlin, D. (1989). Lateral differences in lexical access: Word length vs. stimulus length. Brain and Language, 37, 258-265.

Bruyer, R., \& Ducarme, T. (1990). The field-by-length effect in word processing: A failure to confirm. Intemational Joumal of Neuroscience, 53, 205-208.

Bryden, M. P. (1982). Laterality: Functional asymmetry in the intact brain. New York: Academic Press.

Bryden, M. P. (1986). On the possible dangers of using horizontal word displays in visual field studies. Brain and Cognition, 5, 362-368.

Bryden, M. P., \& Mondor, T. A. (1991). Attentional factors in visual field asymmetries. Canadian Journal of Psychology, 45, 427-447. 
Bryden, M. P., Mondor, T. A., Loken, M., Ingleton, M., \& Bergstrom, K. (1990). Locus of information in words and the right visual field effect. Brain and Cognition, 14, 44-58.

Brysbaert, M. (1991). Algorithms for randomness in the behavioral sciences: A tutorial. Behavior Research Methods, Instruments, \& Computers, 23, 45-60.

Brysbaert, M. (1994a). Behavioral estimates of interhemispheric transmission time and the signal detection method: A reappraisal. Perception \& Psychophysics, 56, 479-490.

Brysbaert, M. (1994b). Interhemispheric transfer and the processing of foveally presented stimuli. Behavioural Brain Research, 64, 151-161.

Brysbaert, M. (1994c). Lateral preferences and visual field asymmetries: Appearances may have been overstated. Cortex, 30, 413-429.

Brysbaert, M., \& d'Ydewalle, G. (1988). Callosal transmission in reading. In G. Lüer, U. Lass, \& J. Shallo-Hoffmann (Eds.), Eye movement research: Physiological and psychological aspects (pp. 246-266). Göttingen, The Netherlands: Hogrefe.

Brysbaert, M., \& d'Ydewalle, G. (1990a). Individual analysis of laterality data. Neuropsychologia, 28, 901-916.

Brysbaert, M., \& d'Ydewalle, G. (1990b). Tachistoscopic presentation of verbal stimuli for assessing cerebral dominance: Reliability data and some practical recommendations. Neuropsychologia, 28, 443455.

Bub, D. N., \& Lewine, J. (1988). Different modes of word recognition in the left and right visual fields. Brain and Language, 33, 161-188.

Burnage, G. (1990). Celex: A guide for users. Nijmegen, The Netherlands: Centre for lexical information.

Chiarello, C., \& Nuding, S. (1987). Visual field effects for processing content and function words. Neuropsychologia, 25, 539-548.

Efron, R. (1990). The decline and fall of hemispheric specialization. Hillsdale, NJ: Erlbaum.

Ellis, A. W., Young, A. W., \& Anderson, C. (1988). Modes of word recognition in the left and right cerebral hemispheres. Brain and Language, 35, 254-273.

Eviatar, Z., Menn, L., \& Zaidel, E. (1990). Concreteness: Nouns, verbs, and hemispheres. Cortex, 26, 611-624.

Eviatar, Z., \& Zaidel, E. (1991). The effect of word length and emotionality on hemispheric contribution to lexical decision. Neuropsychologia, 29, 415-428.

Farid, M., \& Grainger, J. (in press). How initial fixation position influences visual word recognition: A comparison of French and Arabic. Brain and Language.

Faust, M., Kravetz, S., \& Babkoff, H. (1993). Hemispheric specialization or reading habits: Evidence from lexical decision research with Hebrew words and sentences. Brain and Language, 44, 254-263.

Hardyck, C., Chiarello, C., Dronkers, N., \& Simpson, G. (1985). Orienting attention within visual fields: How efficient is interhemispheric transfer? Joumal of Experimental Psychology: Human Perception and Performance, 11, 650-666.

Hellige, J. B. (1986). Visual laterality and the acuity gradient: Potential artifacts and control procedures. Brain and Cognition, 5, 376-396.

Hellige, J. B. (1993). Hemispheric asymmetry: What's right and what's left? Cambridge, MA: Harvard University Press.

Hernandez, S., Nieto, A., \& Barroso, J. (1992). Hemispheric specialization for word classes with visual presentations and lexical decision task. Brain and Cognition, 20, 399-408.

Heron, W. (1957). Perception as a function of retinal locus and attention. American Joumal of Psychology, 70, 38-48.

Holmes, V. M., \& O'Regan, J. K. (1987). Decomposing French words. In J. K. O'Regan \& A. Lévy-Schoen (Eds.), Eye movements: From physiology to cognition (pp. 459-166). Amsterdam: North-Holland.

Kim, H. (1994). Distributions of hemispheric asymmetry in lefthanders and right-handers: Data from perceptual asymmetry studies. Neuropsychology, 8, 148-159.
Kim, H., \& Levine, S. C. (1991). Sources of between-subjects variability in perceptual asymmetries: A meta-analytic review. Neuropsychologia, 29, 877-888.

Kirsner, K., \& Schwartz, S. (1986). Words and hemifields: Do the hemispheres enjoy equal opportunity? Brain and Cognition, 5, 354-361.

Koenig, O., Wetzel, C., \& Caramazza, A. (1992). Evidence for different types of lexical representations in the cerebral hemispheres. Cognitive Neuropsychology, 9, 33-45.

Malamed, F., \& Zaidel, E. (1993). Language and task effects on lateralized word recognition. Brain and Language, 45, 70-85.

McKeever, W. F. (1986). Tachistoscopic methods in neuropsychology. In H. J. Hannay (Ed.), Experimental techniques in human neuropsychology (pp. 167-211). New York: Oxford University Press.

McMullen, P. A., \& Bryden, M. P. (1987). The effects of word imageability and frequency on hemispheric asymmetry in lexical decisions. Brain and Language, 31, 11-25.

Mishkin, M., \& Forgays, D. G. (1952). Word recognition as a function of retinal locus. Joumal of Experimental Psychology, 43, 43-48.

Mohr, B., Pulvermüller, F., \& Zaidel, E. (1994). Lexical decision after left, right and bilateral presentation of function words, content words and non-words: Evidence for interhemispheric interaction. Neuropsychologia, 32, 105-124.

Mondor, T. A., \& Bryden, M. P. (1992). On the relation between visual spatial attention and visual field asymmetries. Quarterly Joumal of Experimental Psychology, 44A, 529-555.

Nazir, T. A., Heller, D., \& Sussmann, C. (1992). Letter visibility and word recognition: The optimal viewing position in printed words. Perception \& Psychophysics, 52, 315-328.

Nazir, T. A., O'Regan, J. K., \& Jacobs, A. M. (1991). On words and their letters. Bulletin of the Psychonomic Society, 29, 171-174.

Orbach, J. (1952). Retinal locus as a factor in the recognition of visually perceived words. American Journal of Psychology, 65, 555562.

O'Regan, J. K. (1981). The convenient viewing position hypothesis. In D. F. Fisher, R. A. Monty, J. W. Senders (Eds.), Eye movements, cognition, and visual perception (pp. 289-298). Hillsdale, NJ: Erlbaum.

O'Regan, J. K., \& Jacobs, A. M. (1992). Optimal viewing position effect in word recognition: A challenge to current theory. Journal of Experimental Psychology: Human Perception and Performance, 18, 185-197.

O'Regan, J. K., Lévy-Schoen, A., Pynte, J., \& Brugaillère, B. (1984). Convenient fixation location within isolated words of different length and structure. Journal of Experimental Psychology: Human Perception and Performance, 10, 250-257.

Radeau, M., \& Morais, J. (1990). The uniqueness point effect in the shadowing of spoken word. Speech Communication, 9, 155-164.

Radeau, M., Morais, J., Mousty, Ph., Saerens, M., \& Bertelson, P. (1992). A listener's investigation of printed word processing. Journal of Experimental Psychology: Human Perception and Performance, 18, 861-871.

Radeau, M., Mousty, Ph., \& Bertelson, P. (1989). The effect of the uniqueness point in spoken word recognition. Psychological Research, 51, 123-128.

Rayner, K., \& Pollatsek, A. (1989). The psychology of reading. Englewood Cliffs, NJ: Prentice-Hall.

Schwartz, S., Montagner, S., \& Kirsner, K. (1987). Are there different methods of lexical access for words presented in the left and right visual fields" Brain and Language, 31, 301-307.

Sprott, D. A., \& Bryden, M. P. (1983). Measurement of laterality effects. In J. B. Hellige (Ed.), Cerebral hemisphere asymmetry: Method, theory, and application (pp. 445-464). New York: Praeger.

Statsoft (1991). Statistica. Tulsa: Statsoft. 
Sugishita, K., Hamilton, C. R., Sakuma, I., \& Hemmi, I. (1994). Hemispheric representation of the central retina of commissurotomized subjects. Neuropsychologia, 32, 399-415.

Trésor de la langue française (1971). Nancy, France: Centre National de Recherche Scientific.

Young, A. W. (1982). Methodological and theoretical bases of visual hemifield studies. In J. G. Beaumont (Ed.), Divided visual field studies of cerebral onganisation (pp. 11-27). London: Academic Press.

Young, A. W., \& Ellis, A. W. (1985). Different methods of lexical access for words presented in the left and right visual hemifield. Brain and Language, 24, 326-358.
Zaidel, E. (1983). Disconnection syndrome as a model for laterality effects in the normal brain. In J. B. Hellige (Ed.), Cerebral hemisphere asymmetry: Method, theory, and application (pp. 95-151). New York: Praeger.
Received August 8, 1995

Revision received January 16, 1996

Accepted January 22, 1996

\section{American Psychological Association SUBSCRIPTION ClaIms INFORMATION}

Today's Date:

We provide this form to assist members, institutions, and nonmember individuals with any subscription problems. With the appropriate information we can begin a resolution. If you use the services of an agent, please do NOT duplicate claims through them and directly to us. PLEASE PRINT CLEARLY AND IN NK IF POSSIBLE.

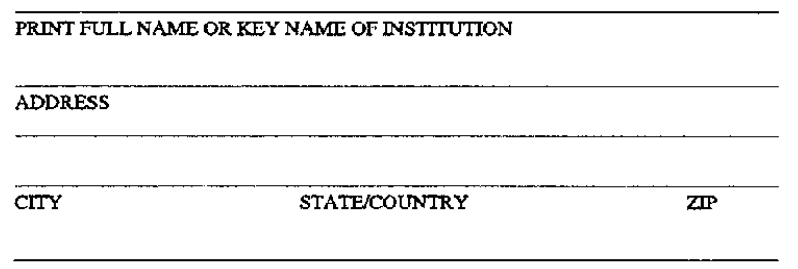

YOUR NAME AND PHONE NUMBER

TITLE
MEMBER OR CUSTOMER NUMBER(MAY BEFOUND ONANY PASTISSUELABEL) DATE YOUR ORDER WAS MAILED (OR PHONED)

PREPAD _CHECK CHARGE

(If possible, send a copy, front and back, of your cancelled check to help us in our research of your claim.)

ISSUES: _ MISSING _ DAMAGED

NUMBER OR MONTH

Thank you. Once a claim is received and resolved, delivery of replacement issues routinely takes 4-6 weeks.

(TO BE FILLED OUT BY APA STAFF)

DATE RECEIVED:

ACTION TAKEN:

STAFF NAME:
DATE OF ACTION:

INV. NO. \& DATE:

LABEL NO. \& DATE:

Send this form to APA Subscription Claims, 750 First Street, NE, Washington, DC 20002-4242

PLEASE DO NOT REMOVE. A PHOTOCOPY MAY BE USED. 